\title{
LIMITATIONS OF DRY FLUE GAS TREATMENT BY SODIUM BICARBONATE: THE INFLUENCE OF FLUE GAS COMPOSITION
}

\author{
BOLESLAV ZACH ${ }^{1,2}$, MICHAEL POHOŘELÝ $^{1,2}$, MICHAL ŠYC $^{1}$, KAREL SVOBODA $^{1}$, \\ ŠÁRKA VÁCLAVKOVÁ ${ }^{1}$, JAROSLAV MOŠKO ${ }^{1,2}$, JIŘİ BRYNDA ${ }^{1,2}$ \& MIROSLAV PUNČOCHÁR̆ ${ }^{1}$ \\ ${ }^{1}$ Department of Environmental Engineering, Institute of Chemical Process Fundamentals of the CAS, \\ Czech Republic \\ ${ }^{2}$ Department of Power Engineering, University of Chemistry and Technology Prague, Czech Republic
}

\begin{abstract}
Waste to energy is nowadays in many countries preferred to landfilling. In areas with low population density, small-scale waste to energy plants can help to avoid large collection areas. However, in small scale, flue gas treatment is very expensive and, therefore, has to be for these purposes simplified. One of the possibilities for flue gas treatment simplification is the use of one reactor for removal of multiple pollutants. In an extreme case, it is possible to realise the removal of solid particles, acidic gases, selective catalytic reduction of $\mathrm{NO}_{\mathrm{x}}$, and catalytic oxidation of polychlorinated dibenzodioxins and furans. In case of suitable flue gas composition and suitable catalyst, it is possible to lower the operation temperature below $180^{\circ} \mathrm{C}$, which could allow the use of activated carbon for mercury capture. However, finding the optimal conditions is a big challenge as they depend on flue gas composition, desired concentrations of pollutants in flue gas after cleaning, and used agents. These conditions can be, therefore, very different according to specific application. To be able to find good compromise conditions, the understanding of the influence of individual operation parameters on all considered processes is necessary. The experimental activity, conducted with real flue gas, was focused on dry sorption of acidic gases with emphasis on the possibility to use simultaneously other cleaning processes. The sorption was realised by sodium bicarbonate and sorbent particles were captured on ceramic filters forming a filter cake containing the sorbent. Different flue gas compositions, temperatures, and sorbent excesses were used. The flue gas composition was measured online and manually taken samples (absorption solutions) were analysed by ion chromatography. Particle size distribution was analysed by laser diffraction. The acquired data was used to assess the limits of simultaneous removal of various pollutants from flue gas in relation to flue gas composition.
\end{abstract}

Keywords: dry flue gas treatment, flue gas composition, sodium bicarbonate, waste-to-energy, dry sorption.

\section{INTRODUCTION}

One of the biggest concerns regarding waste to energy are the emissions of pollutants into the atmosphere. However, if there is to be, in following years, waste management not primarily based on landfills, the construction of new waste to energy plants is going to be inevitable. Since there are also areas with low population density, small scale waste to energy is in some places the only alternative to large collection areas.

Flue gas treatment in small scale tends to be expensive, it is, therefore, reasonable to look for ways to make the flue gas treatment less costly. One possible solution is the simplification of flue gas treatments. The aim is to use one reactor for the removal of as many pollutants as possible. However, compromise conditions may affect the efficiency of removal of individual pollutants, in other terms, cause higher consumption of reagents. In small scale, the increase in operation costs can be outweighed by the reduction in capital costs. To use such reactors efficiently or to be able to decide whether it is suitable to use such flue gas treatment system, it is necessary to know the influence of individual parameters on individual processes of the flue gas treatment system. 


\section{MATERIALS AND METHODS}

\subsection{Experiments}

The experimental unit used for the experimental activity is shown in Fig. 1. The unit is designed for testing of dry treatment of real flue gas. Flue gas is generated in the retort burner. The combustion air is introduced into the retort burner by a mass flow controller. The exact amount of combustion air is, therefore, known. The flue gas composition can be modified by the change in fuel composition. The combustion air is pretreated so it does not contain any impurities that could originate in compressors and the concentration of water vapour in the air is known.

The analysis and sampling of raw flue gas and addition of sorbent is realised in the duct system 1. This part consists of thin pipes to provide high Reynolds number and, therefore, good mixing and transport of mass and heat. It also helps to prevent the formation of deposits in the duct system.

Flue gas treatment process takes place in the filter baghouse. The reactor has a cylindrical shape and flue gas can enter the reactor from two points: tangentially in the upper part (so the process combines barrier filtration with cyclonic effect) and perpendicularly in the lower part through a gas distributor.

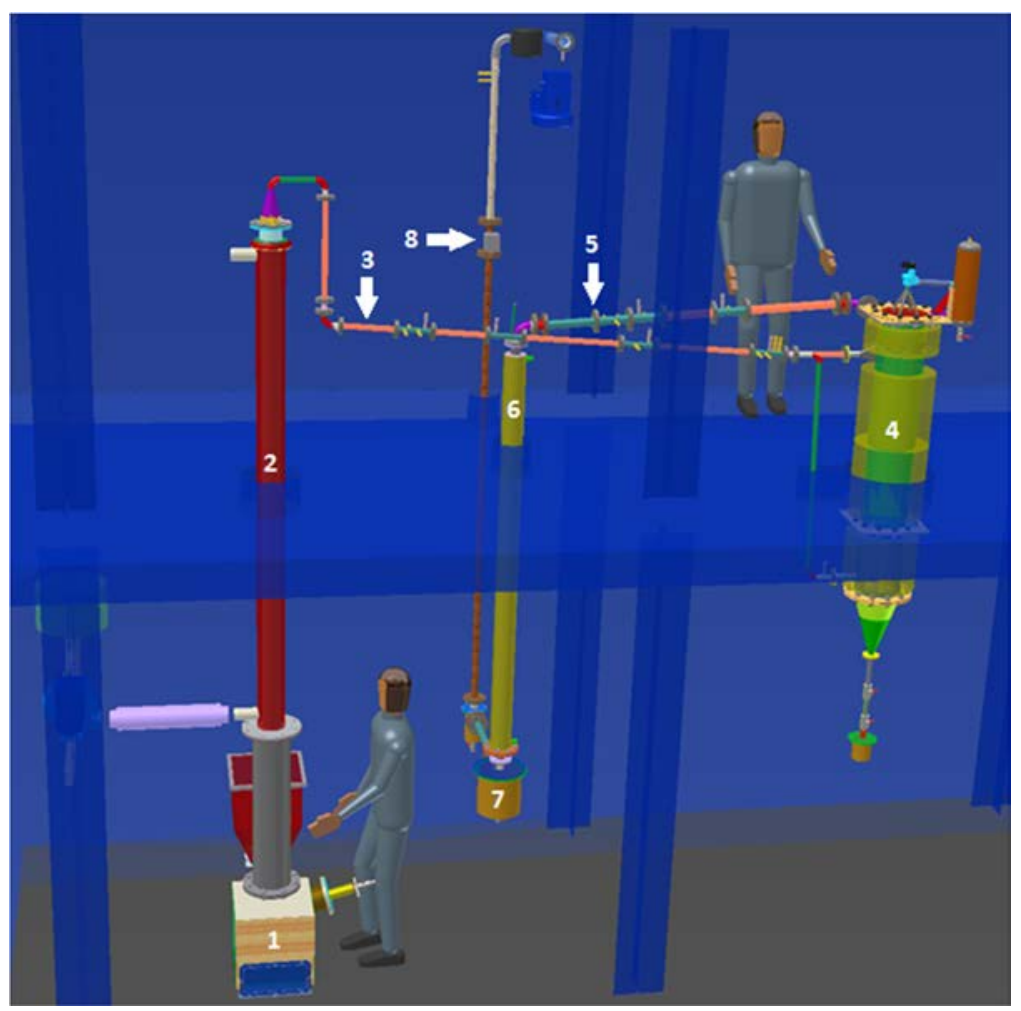

Figure 1: Experimental apparatus; (1) retort burner, (2) co-current air cooler, (3) duct system 1, (4) filter baghouse, (5) duct system 2, (6) counter-current water cooler, (7) condensation vessel, (8) ultrasonic gas flowmeter. 
Up to four filter elements can be placed in the reactor. Their cleaning is executed by pulse valve. When the pressure loss exceeds a tolerable value, the pulse valve lets a sharp pulse of air (or nitrogen) through nozzles in the filter elements. This pulse blows of the filter cake from the elements. The bottom of the reactor is hopper-shaped and is attached to a system of two globe valves that allows to take samples of the residue during operation.

Analysis and sampling of clean flue gas is realised in duct system 2 and heating elements maintain desired temperature in duct systems and filter baghouse.

For the purpose of experiments, $\mathrm{SO}_{2}$ and $\mathrm{HCl}$ removal by sodium bicarbonate was investigated. These two gases are commonly present in flue gas from waste to energy and, in both cases, emission standards apply.

The fuel used during the experiments was based on wood pellets. Their composition was adjusted by addition of sulfur $\left(\mathrm{S}^{0}\right)$ and chlorine $\left(\mathrm{CaCl}_{2}\right)$. The concentration of sulfur in fuel was adjusted by application of a solution of elementary sulfur - solution of elementary sulfur in toluene was sprayed on wood pellets and the toluene was subsequently evaporated. The addition of chlorine was based on the same procedure conducted with water solution of $\mathrm{CaCl}_{2}$. Particle size of used sodium bicarbonate was $10 \mu \mathrm{m}$. Sodium bicarbonate was used because it is suitable for temperatures around $200^{\circ} \mathrm{C}$ [1]. Another often used sorbent, calcium hydroxide, was found to be unsuitable because of low activity at temperatures around $200^{\circ} \mathrm{C}$.

The amount of sorbent fed into the system was regulated to achieve constant concentration of $\mathrm{SO}_{2}$. A typical recording of concentrations is show in Fig. 2. Initial part shows high $\mathrm{SO}_{2}$ concentration prior sorbent feeding, middle part shows concentration of $\mathrm{SO}_{2}$ decreased by sorbent addition, and final part shows return of concentration value to the original point. The oxygen concentration indicates the stability of combustion.

During the experiments, fly ash turned out to be a considerable contributor to the pressure loss of the filter cake. Because the ash content in used fuel (wood pellets) is significantly lower than the ash content in municipal solid waste, it can be presumed that, in the case of real application, the pressure loss in the baghouse will be caused mainly by fly ash and the sorbent will play only a minor role.

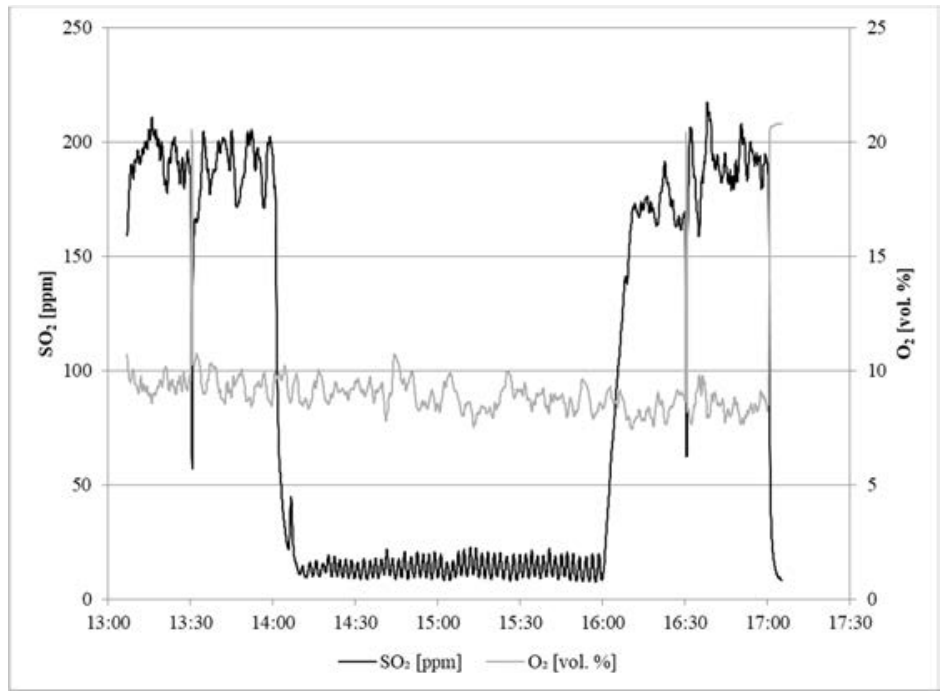

Figure 2: A typical recording of concentrations of $\mathrm{O}_{2}$ and $\mathrm{SO}_{2}$ in flue gas during the experiment. 


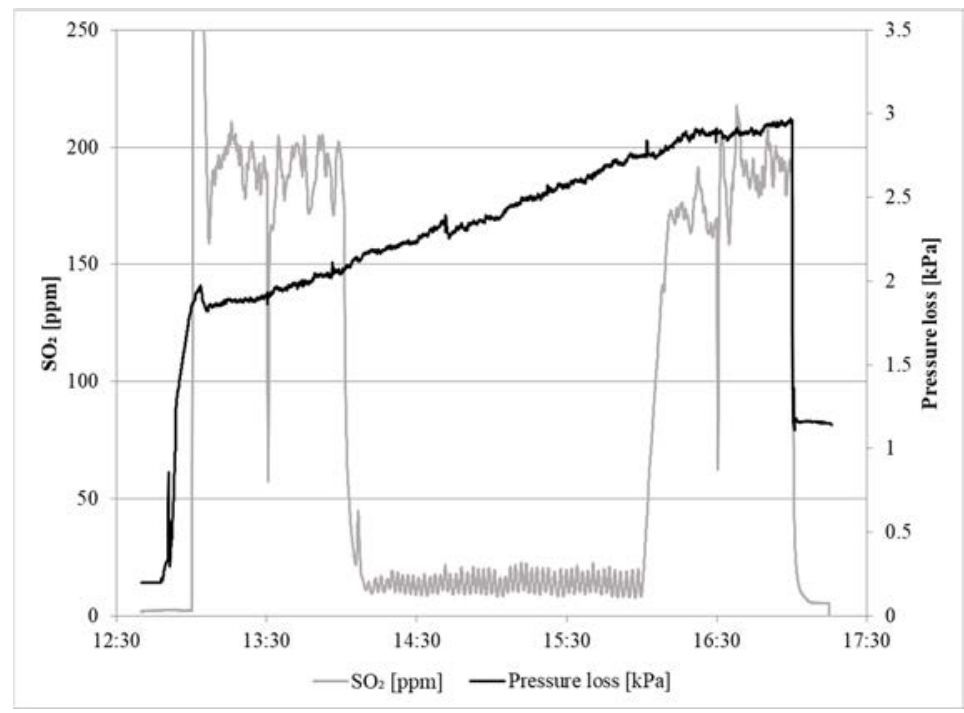

Figure 3: Pressure drop recording during an experiment.

Since this is the case, we have chosen to keep the duration of sorbent feeding period exactly the same for every experiment to make the experiments comparable. The sorbent feeding period was always 2 hours. This duration was chosen so that the period is as long as possible to minimise the impact of initial and end phase of the experiment while keeping the pressure loss reasonable.

Fig. 3 shows the change in pressure loss with time during an experiment with wood pellets. It can be seen that the pressure loss is greatly affected by fly ash as it increases by similar rate even when no sorbent is fed into the system.

\subsection{Analysis}

The analysis of flue gas was conducted online by Horiba PG-350 $\left(\mathrm{O}_{2}, \mathrm{SO}_{2}, \mathrm{NO}_{\mathrm{x}}, \mathrm{CO}, \mathrm{CO}_{2}\right)$ and offline by manual samplings in absorption solutions and subsequent ion chromatography $\left(\mathrm{SO}_{2}, \mathrm{HCl}\right)$. The composition of used sorbent was analysed by SEM-EDX.

\section{RESULTS AND DISCUSSION}

\section{$3.1 \mathrm{HCl}$ and $\mathrm{SO}_{2}$}

Sodium bicarbonate was used to remove $\mathrm{HCl}$ and $\mathrm{SO}_{2}$ from real flue gas. During the experiments, the focus was on the ratio of $\mathrm{HCl}$ and $\mathrm{SO}_{2}$ in the flue gas.

When the $\mathrm{HCl} / \mathrm{SO}_{2}$ ratio in flue gas was increased, the amount of sorbent reacting with $\mathrm{HCl}$ increased whereas in the case of $\mathrm{SO}_{2}$ the trend was opposite as can be seen in Fig. 4. This is partially intuitive, because higher concentration of pollutant promotes its reaction with the sorbent. However, even a small increase in the $\mathrm{HCl} / \mathrm{SO}_{2}$ ratio lead to disproportionate decrease in the fraction of sorbent that reacted with $\mathrm{SO}_{2}$ and Fig. 5 shows that the change in the ratio of acid gas concentrations affected only the removal efficiency of $\mathrm{SO}_{2}$ and, in the case $\mathrm{HCl}$, the relative removed amount was unchanged. 


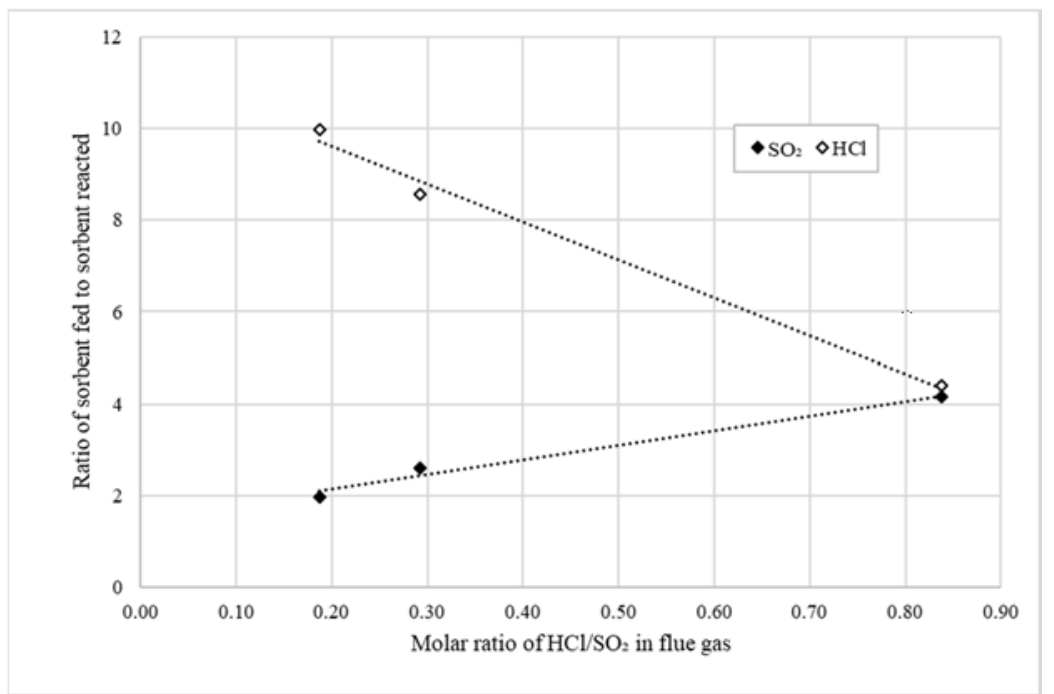

Figure 4: The influence of fuel composition on sorbent selectivity. The concentrations of $\mathrm{SO}_{2}$ in raw and clean flue gas were constant.

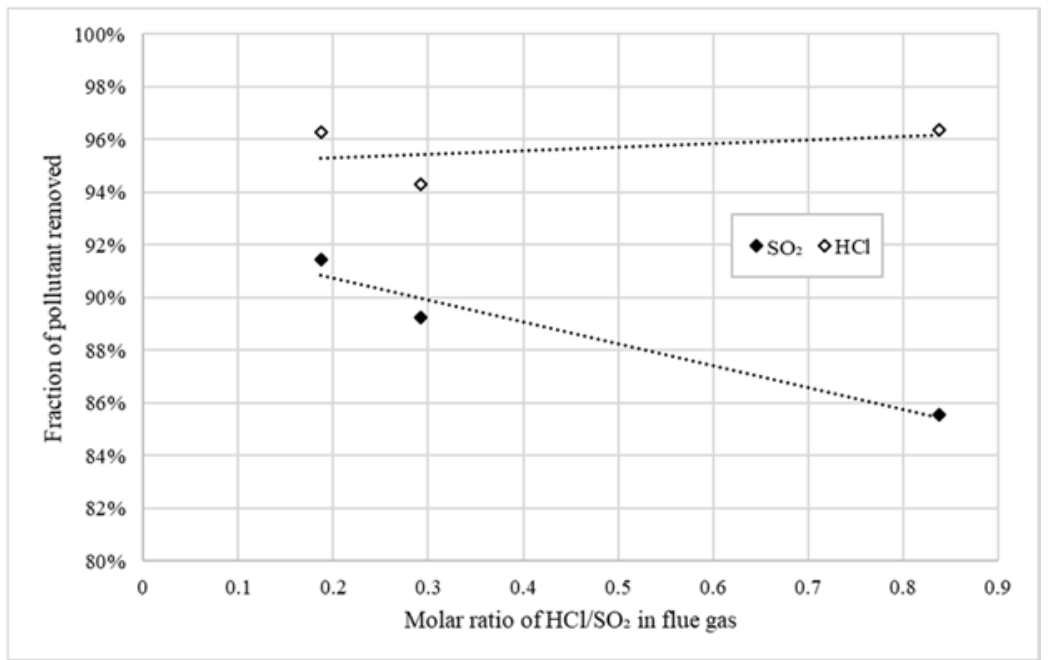

Figure 5: The effect of fuel composition on the removal of pollutants.

That could be caused by higher kinetics of $\mathrm{HCl}$ with $\mathrm{Na}_{2} \mathrm{CO}_{3}$, when $\mathrm{HCl}$ more readily reacts on the easily accessible surface and thereby decreases the removal of $\mathrm{SO}_{2}$. This would also be in agreement with constant removal efficiency of $\mathrm{HCl}$ with increasing ratio of $\mathrm{HCl} / \mathrm{SO}_{2}$ in flue gas (Fig. 5).

According to Verdone and De Filippis [2], the presence of $\mathrm{SO}_{2}$ promotes the removal of $\mathrm{HCl}$. The existence of such phenomenon would provide a good explanation for the results of conducted experiments. 
The promoted reaction with $\mathrm{HCl}$ at the expense of $\mathrm{SO}_{2}$ is an advantage because, in the case of flue gas from waste to energy, the concentration of $\mathrm{HCl}$ is typically higher than the concentration of $\mathrm{SO}_{2}$, moreover, the emission standards for $\mathrm{HCl}$ are generally a few times stricter.

The results showed the optimal operation with concentrations in flue gas of $200 \mathrm{mg} / \mathrm{m}^{3}$ of $\mathrm{HCl}$ and $500 \mathrm{mg} / \mathrm{m}^{3}$ of $\mathrm{SO}_{2}$. In this case, it was possible to achieve in both cases $(\mathrm{HCl}$ and $\left.\mathrm{SO}_{2}\right)$ simultaneously the concentrations corresponding to emission standards $\left(10 \mathrm{mg} / \mathrm{m}^{3}\right.$ for $\mathrm{HCl}$ and $50 \mathrm{mg} / \mathrm{m}^{3}$ for $\mathrm{SO}_{2}$ ).

The value of the concentration of $\mathrm{SO}_{2}$ in flue gas reflects the concentrations normally appearing in flue gas from waste to energy plants. However, in the case of $\mathrm{HCl}$ the concentrations are usually significantly higher. That means that, when $\mathrm{NaHCO}_{3}$ is used for dry flue gas treatment in waste to energy, the $\mathrm{HCl}$ concentration will be determining for the amount of sorbent used and the emission standards for $\mathrm{SO}_{2}$ will be fulfilled excessively. The sorbent will be therefore consumed by the reaction with $\mathrm{SO}_{2}$, which is not required to take place, because the concentration set by emission standards was already met. However, even if the reaction of $\mathrm{SO}_{2}$ with $\mathrm{NaHCO}_{3}\left(\mathrm{Na}_{2} \mathrm{CO}_{3}\right)$ would be quantitative, it would mean an increase in sorbent consumption of only a few percent.

For the considered flue gas $\left(500 \mathrm{mg} / \mathrm{m}^{3}\right.$ of $\mathrm{SO}_{2}$ and $900 \mathrm{mg} / \mathrm{m}^{3}$ of $\left.\mathrm{HCl}\right)$, the difference of $50 \mathrm{mg} / \mathrm{m}^{3}$ of $\mathrm{SO}_{2}$ means one tenth of the original concentration of $\mathrm{SO}_{2}$. The increase in sorbent consumption will, therefore, be $10 \%$. Moreover, if we consider the concentration of $\mathrm{HCl}$, the change in consumed sorbent will be only $2-3 \%$ and, if the raw flue gas concentrations would be higher, the relative change in consumed sorbent would be even lower. In absolute numbers, the sorbent consumption (stoichiometric) is: $2.7 \mathrm{~g} / \mathrm{m}^{3}$ (for 500 $\mathrm{mg} / \mathrm{m}^{3}$ of $\mathrm{SO}_{2}$ and $900 \mathrm{mg} / \mathrm{m}^{3}$ of $\mathrm{HCl}$ in the raw flue gas); the increase in sorbent consumption caused by excessive reaction with $\mathrm{SO}_{2}$ is $0.07 \mathrm{~g} / \mathrm{m}^{3}$.

The overall sorbent conversion during experiments with concentrations similar to those usually appearing in flue gas from waste to energy ranged usually from 60 to $70 \%$. These number are, however, specific for the experimental setup. The experiments were different from the processes that take place in real units. This means that the absolute numbers are not relevant for real application, but the trends can be used to set the optimal conditions of the flue gas treatment system.

\subsection{Other components}

Besides nitrogen and oxygen, the major components in flue gas are water vapour and carbon dioxide.

The presence of water vapour affects the thermodynamic equilibrium of pollutants in the system with $\mathrm{Na}_{2} \mathrm{CO}_{3}$. However, the equilibrium concentrations are in any case sufficiently low and the removal efficiency (sorbent utilisation) is not determined by thermodynamics but by kinetics, which did not appear to be affected by the content of water vapour.

Carbon dioxide, on the other hand, affects the formation of sorbent surface during the decomposition of $\mathrm{NaHCO}_{3}$ to $\mathrm{Na}_{2} \mathrm{CO}_{3}$. According to Keener et al. [3] the formation is affected when the partial pressure of $\mathrm{CO}_{2}$ is above 0.01 bar.

That would mean that, in the case of flue gas, $\mathrm{CO}_{2}$ would definitely play a role during the surface formation.

\section{CONCLUSION}

The experiments with various $\mathrm{HCl}: \mathrm{SO}_{2}$ ratios in flue gas showed that $\mathrm{NaHCO}_{3}\left(\mathrm{Na}_{2} \mathrm{CO}_{3}\right)$ reacts more readily with $\mathrm{HCl}$, which is suitable for flue gas from waste to energy as it contains 
usually higher contents of $\mathrm{HCl}$ and the emission standards are stricter. The emission standards for $\mathrm{HCl}$ and $\mathrm{SO}_{2}\left(10 \mathrm{mg} / \mathrm{m}^{3}\right.$ and $50 \mathrm{mg} / \mathrm{m}^{3}$ respectively $)$ were achieved with flue gas that contained $200 \mathrm{mg} / \mathrm{m}^{3}$ of $\mathrm{HCl}$ and $500 \mathrm{mg} / \mathrm{m}^{3}$ of $\mathrm{SO}_{2}$. However, typical flue gas from waste to energy has higher $\mathrm{HCl}: \mathrm{SO}_{2}$ ratio, which will lead to excessive reaction with $\mathrm{SO}_{2}$. This will increase the sorbent consumption. Considering the difference in reacted $\mathrm{SO}_{2}$ and the sorbent conversion, the increase will be probably lower than one percent of total sorbent consumption, which is quite low in comparison with other factors.

\section{ACKNOWLEDGEMENT}

This research was conducted within Waste to Energy Competence Centre funded by the Technology Agency of the Czech Republic (project TE02000236) and co-financed from Operational Programme Research, Development and Education of the Ministry of Education, Youth and Sports of the Czech Republic, reg. number CZ.02.2.69/0.0/0.0/16_027/0007931.

\section{REFERENCES}

[1] Thomé-Kozmiensky, K.J. \& Thiel, S., Waste Management - Waste-to-Energy. TK Verlag Karl Thomé-Konzmiensky. Neuruppin, 5 pp. 193-220, 2015.

[2] Verdone, N. \& De Filippis, P., Reaction kinetics of hydrogen chloride with sodium carbonate. Chemical Engineering Science, 61(22), pp. 7487-7496, 2006. https://doi.org/ 10.1016/j.ces.2006.08.023

[3] Keener, T.C., Frazier, G.C. \& Davis, W.T., Thermal decomposition of sodium bicarbonate. Chemical Engineering Communications, 33(1-4), pp. 93-105, 1985. https://doi.org/10.1080/00986448508911162 